\title{
Once-daily atomoxetine may reduce attention deficit hyperactivity disorder symptoms in children and adolescents
}

\author{
Michelson D, Allen A, Busner J et al. Once daily atomoxetine treatment for children and adolescents with attention deficit \\ hyperactivity disorder: A randomized, placebo-controlled study. Am J Psych 2002 Nov;159:1896-901.

\section{QUESTION: How effective is once-daily atomoxetine for children and adolescents with attention deficit hyperactivity disorder (ADHD)?}

Source of funding: Funded by Eli Lilly and Company

For correspondence: D Michelson, Lilly Corporate Center, Indianapolis, USA.

\section{Design}

Randomised controlled trial. Participants, clinicians and outcome assessors were blind to treatment allocation.

\section{Setting}

9 outpatient centres in the United States; timeframe not specified.

Treatment response and remission in children and adolescents with ADHD receiving 6 weeks of daily atomoxetine or placebo

\begin{tabular}{lcccc} 
& $\begin{array}{c}\text { Atomoxetine } \\
\%(n=84)\end{array}$ & $\begin{array}{c}\text { Placebo } \\
\%(n=83)\end{array}$ & $\begin{array}{c}\text { Number needed to treat } \\
\text { with atomoxetine to } \\
\text { benefit 1 person } \\
(95 \% \mathrm{Cl})\end{array}$ & $\begin{array}{c}\text { Absolute benefit } \\
\text { increase \% } \\
(95 \% \mathrm{Cl})\end{array}$ \\
\hline Response & 59.5 & 31.3 & $4(2$ to 7$)$ & $28.2(13.7$ to 42.7$)$ \\
\hline Remission & 28.6 & 9.6 & $5(3$ to 13$)$ & $19.0(7.4$ to 30.6$)$ \\
\hline
\end{tabular}

\section{Participants}

170 children aged between 6 and 16 years who met the DSM-IV criteria for ADHD and had a symptom severity score at least 1.5 standard deviations above age and gender norms. 29\% were female; mean age 10 years; $55 \%$ previously treated with a stimulant.

Adverse effects in children and adolescents with ADHD receiving 6 weeks of daily atomoxetine or placebo

\begin{tabular}{lcccc} 
& $\begin{array}{c}\text { Atomoxetine } \\
\%(n=85)\end{array}$ & $\begin{array}{c}\text { Placebo } \\
\%(n=85)\end{array}$ & $\begin{array}{c}\text { Number needed to treat } \\
\text { with atomoxetine to } \\
\text { harm } 1 \text { person }(95 \% \mathrm{Cl})\end{array}$ & $\begin{array}{c}\text { Absolute risk } \\
\text { increase } \% \\
(95 \% \mathrm{Cl})\end{array}$ \\
$\begin{array}{l}\text { Decreased } \\
\text { appetite }\end{array}$ & 20.0 & 5.9 & $7(4$ to 24$)$ & $14.1(4.2$ to 24.0$)$ \\
\hline Vomiting & 15.3 & 1.2 & $7(5$ to 16$)$ & $14.1(6.1$ to 22.1$)$ \\
\hline Nausea & 11.8 & 2.4 & $11(6$ to 55$)$ & $9.4(1.8$ to 17.0$)$ \\
\hline Asthenia & 10.6 & 1.2 & $11(6$ to 41$)$ & $9.4(2.5$ to 16.3$)$ \\
\hline Dyspepsia & 9.4 & 0.0 & $11(6$ to 31$)$ & $9.4(3.2$ to 15.6$)$ \\
\hline
\end{tabular}

\section{COMMENTARY}

ADHD is a common behavioural disorder in childhood. Although stimulants effectively control symptoms, their use has been limited due to the need for evening and early morning coverage, adverse effects and concerns about abuse and diversion. Stimulant alternatives may address these limitations. Atomoxetine is a presynatic norepinephrine reuptake inhibitor found to be effective in 3 previous placebo-controlled trials. It was recently approved for use by the US Food and Drug Administration for the treatment of ADHD in children, adolescents and adults. In this study, children receiving atomoxetine once-daily had superior symptom improvements, minimal dropout and modest adverse effects.

This study suggests that once-daily dosing in the morning was associated with ADHD symptom control well into the evening, comparable in magnitude with twice-a-day dosing. The availability of a non-stimulant once-daily pharmacologic treatment is significant. As atomoxetine is not scheduled by the Drug Enforcement Administration, it may have lower potential for abuse or diversion. The increased prevalence of ADHD among individuals with substance use disorders makes the availability of a non-stimulant alternative even more compelling. The ability to provide samples or to call in prescriptions and multiple refills adds to its convenience. Since atomoxetine is a norepinephrine modulating agent, it could be used with primarily dopaminemodulating stimulants.

The study has some limitations, however. There is no direct comparison with the twice-daily dosing or correlation of efficacy with pharmacokinetic data. Long-term data are not available. Given the significant effect sizes in stimulant trials, the relative efficacy of atomoxetine versus stimulants can only be approximated. Head-to-head comparisons are needed to establish the place of atomoxetine in ADHD treatment, either as a tertiary agent for stimulant failures or as a first-line agent. Future studies could also examine long-term safety and benefits in specialised populations such as people with ADHD plus substance use disorders.

\section{Intervention}

After a minimum 5 day medication free evaluation period, participants received 6 weeks of once-daily atomoxetine or placebo. For the first 3 days, the atomoxetine dose was $0.5 \mathrm{mg} / \mathrm{kg} /$ day. This was increased to $0.75 \mathrm{mg} / \mathrm{kg} /$ day for the remainder of the first week and $1 \mathrm{mg} / \mathrm{kg}$ /day thereafter. After 4 weeks, participants with a Clinical Global Impression (CGI) severity score of 2 or more received $1.5 \mathrm{mg} / \mathrm{kg} /$ day.

\section{Main outcome measures}

The primary outcome was total score on the 18-item ADHD Rating Scale-IV. Treatment response was defined as $25 \%$ or greater reduction from baseline on total ADHD Rating Scale-IV score. Remission was defined as a CGI severity score of 1 or 2 .

\section{Main results}

Participants receiving atomoxetine had greater mean reductions in ADHD Rating Scale-IV scores compared to placebo. Treatment response and remission were superior with atomoxetine compared to placebo (response odds ratio $3.2,95 \%$ CI 1.6 to 6.4 ; remission odds ratio $3.8,95 \%$ CI 1.5 to 10.3 ; table). Children receiving atomoxetine were more likely to report decreased appetite, vomiting, nausea, asthenia and dyspepsia (table).

\section{Conclusions}

Once-daily atomoxetine had a similar treatment effect size (0.71) to previous studies of twice-daily administration. Once-daily atomoxetine may reduce ADHD symptoms, but has some adverse gastrointestional effects. 